\title{
Disentangling Investment Returns and Stock Returns: The Importance of Time-to-Build*
}

\author{
Lars-Alexander Kuehn \\ Tepper School of Business \\ Carnegie Mellon University
}

March 5, 2009

\begin{abstract}
I provide new evidence on the failure of the Q-theory. The Q-theory implies the state-by-state equivalence of stock and investment returns - a important implication of many asset pricing models. Using aggregate US data, I find there exists a realistic parameterization of the aggregate production and adjustment cost function such that empirical investment returns have first and second moments similar to historical US stock returns. Investment and stock returns are negatively correlated, however, contradicting the Q-theory. This paper also proposes a rational explanation for this finding. A general equilibrium model with production, in which investment projects involve time-to-build, can rationalize these findings. The model is also able to explain the negative correlation of investment growth and stock returns at the aggregate level - an observation that has been interpreted as evidence for irrational markets since it cannot be reconciled with the Q-theory of investment.
\end{abstract}

JEL Classification: E32, G12

Keywords: Real investments, time-to-build, market inefficiency.

${ }^{*}$ This paper is the first chapter of my doctoral dissertation at The University of British Columbia. I am grateful to my thesis committee Murray Carlson, Adlai Fisher, Henry Siu and Tan Wang for constant support and encouragement. I also thank Paul Beaudry, Urban Jermann, Michael Mueller and seminar participants at UBC and the 2006 Northern Finance Association Meeting for valuable comments and discussions. Contact information: 5000 Forbes Avenue, Pittsburgh, PA 15213, kuehn@cmu.edu. 


\section{Introduction}

The workhorse of the real investment literature is the Q-theory of investment based on continuous adjustment costs. ${ }^{1}$ In this paper, I provide new evidence on the failure of the Q-theory. The Q-theory implies the state-by-state equivalence of stock and investment returns - returns from investment in capital reflect the firm's tradeoff between the investment's marginal costs and marginal benefits whereas stock returns are the consumer's tradeoff of investing in the stock market. The equivalence of these two returns is a important (but overlooked) implication of many asset pricing models, for instance, Cox, Ingersoll, and Ross (1985), Gomes, Kogan, and Zhang (2003), Hall (2001), Jermann (1998, 2005), and Liu, Whited, and Zhang (2007).

Using aggregate US data, I find that there exists a realistic parameterization of the aggregate production and Q-theory based adjustment cost function such that empirical investment returns have the similar first and second moments as historical US stock returns, supporting the Q-theory. However, state-by-state equivalence also implies that investment and stock returns are perfectly positively correlated. Yet in the data, they are negatively correlated.

Another prediction of the Q-theory is that investment growth and stock returns are positively correlated. When discount rates fall, investment increases in value and thus firms increase investment. At the same time, stock prices appreciate, leading to positive comovement with investment growth. But, empirically, this correlation is negative contradicting the Q-theory. ${ }^{2}$ Both findings have led researchers to suggest that firms irrationally reduce investments when the stock market signals good times. ${ }^{3}$

The goal of the paper is to rationalize these empirical regularities in a general equilibrium model with production. This paper contributes to a strand of literature which differentiates between the effect of irrational and rational market forces on real investment - the importance is nicely summarized by Baker, Ruback, and Wurgler (2006):

\footnotetext{
${ }^{1}$ Important contributions include Hayashi (1982), Barro (1990), Abel and Eberly (1994), Gilchrist and Himmelberg (1995), and Erickson and Whited (2000).

${ }^{2}$ See also Lamont (2000) for recent evidence.

${ }^{3}$ More empirical evidence suggesting that firm investment is sensitive to proxies for mispricing is contained in Baker, Stein, and Wurgler (2003), Farhi and Panageas (2004), Gilchrist, Himmelberg, and Huberman (2005), and Polk and Sapienza (2009).
} 
Of paramount importance are the real consequences of market inefficiency. It is one thing to say that investor irrationality has an impact on capital market prices, or even financing policy, which lead to transfers of wealth among investors. It is another to say that mispricing leads to underinvestment, overinvestment, or the general misallocation of capital and deadweight losses for the economy as a whole.

I show that a production economy with time-to-build can explain these empirical facts. Time-to-build captures the idea that investment projects are not completed instantaneously. Instead, firms have to allow for several quarters to expand capacity. ${ }^{4}$ When I compute Qtheory based investment returns on simulated data from the time-to-build model, they are negatively correlated with simulated stock returns, as in the data. Moreover, the model replicates the empirical negative correlation between stock returns and investment growth. The time-to-build model therefore provides a rational explanation for an empirical fact, which some researchers have interpreted as evidence for irrational markets.

To keep my model as simple as possible, I consider a two period time-to-build framework where the household has time-separable power utility. In a two period time-to-build specification firms pay for a new project for two periods and the new project becomes productive in the third period. Importantly, the timing of the investment costs is critical to generating the observed negative correlation between investment growth and stock returns. When most costs are incurred toward the end of the construction period of a new project, the correlation is negative. Moreover, the empirical investment literature supports this assumption. For instance, Koeva (2001) reports that in the first year roughly $10 \%$ and in the second year $90 \%$ of the costs are incurred. ${ }^{5}$

In contrast to the traditional exchange economy, the supply of capital is endogenously determined in a production economy and its elasticity determines risk premia. Time-to-

\footnotetext{
${ }^{4}$ The empirical investment literature also provides plenty of direct evidence for time-to-build. For instance, Mayer (1960) conducts a survey of 110 companies and finds that the average length of the time between the decision to build a plant and its completion is 21 months. Montgomery (1995a,b) uses survey data collected by the U.S. Department of Commerce to construct the completion pattern for nonresidential structures between 1961 and 1991. He finds that the construction period averages between 5 and 6 quarters. Further evidence is presented in Mayer (1960), Jorgenson and Stephenson (1967), Ghemawat (1984), and Koeva (2000).

${ }^{5}$ Similar evidence is contained in Christiano and Vigfusson (2003) and Zhou (2000).
} 
build affects the elasticity of capital and thus risk premia in the following way. After a positive technology shock, firms initiate new investment projects to take advantage of higher productivity. Time-to-build implies that there is a lag between the investment decision and when the new project becomes productive. Consequently, the capital stock is fully inelastic in the short-term and excess returns are high. High expected excess returns lower prices and therefore lead to low current realized returns. Since most investment costs are incurred in the period after the shock, both realized returns and investment expenditures are low in the period of the shock. This mechanism leads to a positive correlation between returns and investments, contradicting the empirical evidence.

However, time-to-build also affects the risk-free rate. In the period of a positive shock, investment expenditures cannot increase immediately, but they do so with a lag. To ensure market clearing in equilibrium, consumption has to absorb the positive shock, but falls afterwards. This negative expected consumption growth necessitates a low risk-free rate because the household would like to sell the bond to smooth consumption over time. The low risk-free rate increases the stock price and realized returns. The effects of the risk-free rate and the risk premium on current realized returns work in opposite directions. I find, however, that the risk-free rate effect dominates the risk premium effect. As a result, realized returns and investments are negatively correlated, as in the data.

This general equilibrium mechanism is in stark contrast to partial equilibrium considerations where the pricing kernel is exogenous. In partial equilibrium models, time-to-build affects the riskiness of the firm and thus risk premia. In general equilibrium, the endogeneity of the pricing kernel implies that time-to-build also affects the risk-free rate, which is constant in a partial equilibrium model. This additional channel is crucial to generate the observed negative correlation between investment growth and realized equity returns.

In a general equilibrium model with time-to-build, stock returns reflect not only the value of its productive capital but also the value attributed to ongoing investment projects that have not become productive yet. As a result, average $\mathrm{Q}$ deviates from marginal $\mathrm{Q}$, creating a wedge between investment returns and stock returns. When I compute Q-theory based investment 
returns on simulated data from the time-to-build model, they are negatively correlated with simulated stock returns, as in the data. This result arises since Q-theory based investment returns are mainly driven by changes in the investment rate which are negatively correlated with stock returns.

The standard time-to-build model has the drawback that it implies an oscillating optimal investment policy. After a positive shock, it is optimal for the firm to iterate between large and small investment projects, because it thereby smoothes the average investment costs over time. This implication is counterfactual. To overcome this drawback, I introduce adjustment costs into the model. The standard adjustment cost function, which is defined in terms of the investment rate, the ratio of investment to capital, does not alleviate the problem. In contrast, I assume that the firm faces adjustment costs in the investment growth rate. ${ }^{6}$ As a result, the firm is penalized for iterating between small and large projects, because in that case the investment growth rate varies greatly over time.

The time-to-build model with adjustment costs produces persistent investment growth after a positive technology shock, as observed in the data. The model is able to explain three empirical facts of aggregate data: $(i)$ the negative comovement of stock returns and investment growth, $(i i)$ the prolonged positive correlation between stock returns and future investment growth, and ( $i i i)$ the negative correlation between investment growth and future stock returns.

\section{Related Literature}

This paper is closely related to the real business cycle literature which tries to explain stock market phenomena in a production economy. In line with the equity premium puzzle in an endowment economy, Rouwenhorst (1995) demonstrates the failure of the standard RBC model to account for the equity premium. Jermann (1998) and, more recently, Boldrin, Christiano, and Fisher (2001) show that business cycle models can generate a reasonable equity premium when they are enhanced with frictions. The key insight of these papers is

\footnotetext{
${ }^{6}$ It is important to note that adjustment costs in the investment growth rate do not conform with the Q-theory of investment. Specifically, average and marginal Q do not aline under constant returns to scale. Consequently, this specification is not rejected by the empirical findings of this paper.
} 
that frictions in the capital market as well as modifications of preferences are necessary. Both papers assume the agent has internal habit utility. Jermann (1998) includes Q-theory based capital adjustment costs, which I test in this paper, and Boldrin, Christiano, and Fisher (2001) inter-sector capital and labor immobility. ${ }^{7}$

Time-to-build was introduced into a business cycle model by Kydland and Prescott (1982). They assume that it takes four quarters for an investment project to be finished and the investment costs are spread evenly over the investment project horizon. More recently, Christiano and Todd (1996) argue that in real life most of the investment costs are incurred at the end of the project. Their reasoning is that most investment projects begin with a lengthy planning period, which is less resource-intensive than the actual construction phase of the project. ${ }^{8}$ Christiano and Vigfusson (2003) employ frequency domain tools to estimate and test a business cycle model with time-to-build. They confirm the importance of time-to-build to explain business cycle variations. In addition, they estimate that the business cycle model, which gives the best fit of the data, has most investment costs due at the end of the project - confirming the assumption of this paper. Similar results are contained in Zhou (2000) and Koeva (2001), who estimate the Euler equation of a time-to-build model on investment data.

Further evidence in favor of investment lags is contained in Lamont (2000) and Lettau and Ludvigson (2002). Lamont (2000) shows that investment plans instead of actual investment forecast stock returns because investment plans can react immediately to news and are not affected by investment lags. Lettau and Ludvigson (2002) demonstrate that CAY forecasts investment growth at long horizons because the predictability of investment growth at short horizons might be distorted by investment lags.

In a closely related paper, Cochrane (1991) also computes Q-theory based investment returns coming from the firm's optimality conditions. He uses the production based model to examine why stock returns are forecastable by business cycle related variables and link between stock returns and subsequent economic activity. Similar to Cochrane (1991), Liu,

\footnotetext{
${ }^{7}$ More recent contributions are Danthine and Donaldson (2002), Lettau (2003), Christiano and Fisher (2003), and Guvenen (2004).

${ }^{8}$ Christiano and Todd (1996) call their specification time-to-plan because of the different timing of the investment costs compared to the assumption of Kydland and Prescott (1982). In this paper, I use the words time-to-build and time-to-plan synonymously, even though time-to-plan would be more precise.
} 
Whited, and Zhang (2007) estimate investment returns for the cross-section of firms and find evidence in favor the Q-theory. ${ }^{9}$ In contrast, this paper studies the correlation pattern between investment returns and stock returns which has been ignored by previous studies. Furthermore, I provide an economic mechanism explaining the negative correlation between investment and stock returns.

This paper is also related to the literature trying to explain the cross-sectional predictability of returns by their book-to-market ratio. In partial equilibrium models, Berk, Green, and Naik (1999), Carlson, Fisher, and Giammarino (2004), Zhang (2005), and Cooper (2006) explore the investment decision of dynamically optimizing firms. These papers differ in the investment frictions they entertain to generate a realistic cross-section of returns. Importantly, they only consider instantaneous investment. In a general equilibrium model, Kogan (2001) analyzes the effects of irreversible investment on stock returns. Kogan (2004) adds an upper bound on the rate of investment to ensure that investment cannot occur instantaneously. His specification, however, does not allow to vary the timing of the investment costs, which is the crucial element of this paper.

The effect of time-to-build on the exercise thresholds of real options has been examined by Majd and Pindyck (1987), and Bar-Ilan and Strange (1996). These authors find that investment lags reduce the option value of waiting because of the opportunity costs of waiting for the new productive asset. Carlson, Fisher, and Giammarino (2007) provide evidence that investment commitment in long-term projects is important to explain the dynamics of stock return betas around SEOs in a real option setting.

The road map of the paper is as follows. In Section 2, I test the Q-theory of investment by estimating investment returns. In Section 3, I present the time-to-build model and derive its optimality conditions. Section 4 contains simulation results and the asset pricing implication. Section 5 concludes.

\footnotetext{
${ }^{9}$ Cochrane (1996), Gomes, Yaron, and Zhang (2006), and Li, Vassalou, and Xing (2006) test whether investment returns are priced in the cross-section of returns.
} 


\section{Empirical Findings}

The goal of this section is to estimate investment returns based on the widely used capital adjustment cost framework. Capital adjustment costs are the key ingredient of the Q-theory of investment. This empirical exercise is therefore a test of the Q-theory.

In the first subsection, I derive the investment return based on concave adjustment costs in a partial equilibrium setting. In the second subsection, I estimate investment returns for gross investment, nonresidential and residential investment. In the last subsection, I also analyze the correlation between stock returns and investment growth rates.

\subsection{A Neoclassical Production-Based Asset Pricing Model}

Production-based asset pricing models are derived from firm's optimal investment decision. The firm's problem can be stated as maximizing firm value $P_{t}$ by optimally choosing future real investment $I_{t}$

$$
P_{t}=\max _{\left\{I_{t+s}\right\}_{s=1}^{\infty}} \mathbb{E}_{t}\left[\sum_{s=1}^{\infty} \frac{\Lambda_{t+s}}{\Lambda_{t}} D_{t+s}\right] \quad D_{t}=Y_{t}-I_{t}-l_{t} N_{t}
$$

where $\Lambda_{t}$ denotes the pricing kernel and $D_{t}$ the dividend payment to the stock holder. Dividends are defined as the residual payment after subtracting investment expenditures $I_{t}$ and labor costs, which are hours-worked $N_{t}$ times wage rate $l_{t}$, from output $Y_{t}$. Output is determined by a constant returns to scale Cobb-Douglas production function $F$

$$
Y_{t}=e^{z_{t}} F\left(K_{t}, N_{t}\right) \quad F\left(K_{t}, N_{t}\right)=K_{t}^{\alpha} N_{t}^{1-\alpha}
$$

where $K_{t}$ denotes capital, $z_{t}$ an exogenous technology shock, and $\alpha$ the capital share of production.

Following the Q-theory of investment, firms incur adjustment costs when they invest. There are two common ways to model adjustment costs. Either, adjustment costs reduce current dividends and are subtracted from output as a cost in Equation (1); or adjustment costs impact the dynamics of the capital stock capital stock and future capital grows by less than the firm pays for. I follow the second approach since it is a direct test of Jermann (1998) 
and the functional form of the adjustment costs allows more flexibility. Specifically, the law of motion for capital is

$$
K_{t+1}=(1-\delta) K_{t}+G\left(I_{t}, K_{t}\right)
$$

where $\delta$ denotes depreciation and $G$ is a constant returns to scale adjustment cost function given by

$$
G\left(I_{t}, K_{t}\right)=\left(\frac{a_{1}}{1-1 / \xi}\left(\frac{I_{t}}{K_{t}}\right)^{1-1 / \xi}+a_{2}\right) K_{t}
$$

This function is concave in $I$ and decreasing in $K$ and thus captures the notion that it is more costly to change the capital stock quickly. The parameter $\xi$ is the elasticity of investmentcapital ratio with respect to marginal $\mathrm{Q}$ and controls the concavity of the function. The concavity of $G$ also implies irreversibility of investment because $G$ is not defined for negative $I_{t}$. As noted by Hayashi (1982), this feature does not affect the dynamics, since optimal investment is never negative at the aggregate level.

As a consequence of the capital adjustment costs, a Tobin's Q interpretation arises. Marginal $\mathrm{Q}$ is the ratio of the marginal value of an additional unit of capital, $\Gamma_{t}$, to the price of a unit of capital, $\Lambda_{t}$. Formally, marginal Q, denoted by $q_{t}$, is defined as

$$
q_{t}=\frac{\Gamma_{t}}{\Lambda_{t}}
$$

where $\Gamma_{t}$ is the Lagrange multiplier on (3) and therefore the value of capital. Investment should take place when marginal $\mathrm{Q}$ is greater than one, $q_{t}>1$, and destruction of capital when marginal $\mathrm{Q}$ is less than one, $q_{t}<1$. Adjustment costs prevent the firm from adjusting the capital stock every period to its optimal level, resulting in a time-varying marginal $\mathrm{Q}$ which deviates from unity.

The solution to the firm's optimization problem (1) can be characterized by the Euler equation

$$
\mathbb{E}_{t}\left[\frac{\Lambda_{t+1}}{\Lambda_{t}} R_{t+1}^{I}\right]=1
$$

where

$$
R_{t+1}^{I}=\frac{M P K_{t+1}+q_{t+1}\left(G_{2}\left(I_{t+1}, K_{t+1}\right)+(1-\delta)\right)}{q_{t}}
$$


defines the investment return on capital; $M P K_{t+1}=e^{z_{t+1}} F_{1}\left(K_{t+1}, N_{t+1}\right)$ is the marginal product of capital and $G_{i}$ denotes the partial derivative of $G$ with respect to its $i$-th element. The investment return is the ratio of tomorrow's marginal productivity plus tomorrow's capital gains divided by current marginal costs. Accordingly, it reflects the firm's intertemporal tradeoff of investing.

One of the standard neoclassical assumptions is constant returns to scale (CRS). This innocuous-looking assumption has, however, major asset pricing implications. Hayashi (1982) proves in a non-stochastic setting and Abel and Eberly (1994) in a stochastic setting that when production function and adjustment cost function are both CRS, marginal $\mathrm{Q}$ equals Tobin's average $\mathrm{Q}$ which is . As a result, firm value is given by

$$
P_{t}=q_{t} K_{t+1}
$$

This equation says that firm value is the value of capital in terms of the numeraire times the amount of capital. Substituting (8) into the investment return (7) and assuming that labor is paid its marginal product in a competitive market, it follows that

$$
R_{t+1}^{I}=\frac{P_{t+1}+D_{t+1}}{P_{t}}=R_{t+1}^{E}
$$

and hence the investment return on capital is equal to the stock return $R_{t+1}^{E}$ state by state. This equivalence was first noticed by Restoy and Rockinger (1994).

Different adjustment cost functions, or more generally, different production-based asset pricing models, result in different functional forms for investment returns. This fact implies that investment returns are not uniquely identified but are model dependent, whereas stock returns are not. Nevertheless, one can rebut production-based asset pricing models for their implications for investment returns. That is precisely done here.

\subsection{Data}

To construct an investment return time-series, I use aggregate quarterly US NIPA data covering the period 1947 Q1 until 2005 Q4. Output $Y_{t}$ is real GDP minus government expenditure. I compute the investment return based on real gross private domestic investment and the 
two subcategories real private nonresidential and residential fixed investment. I leave out the third subcategory which is changes in private inventories.

Gross private investment comprises nonresidential and residential fixed investment as well as changes in private inventories. Nonresidential fixed investment comprises structures as well as equipment and software. Nonresidential structures are, for instance, new constructions (e.g., hotels or mining explorations), improvements to existing structures, and brokers' commissions of sales of structures. Nonresidential equipment and software are purchases by private business of new machinery, equipment, furniture, vehicles, and computer software. Residential fixed investment consists, for instance, of new construction of permanent single and multi family units, improvements to housing units, and brokers' commissions on the sale of residential property.

The capital stock time-series is constructed by aggregating investment following (3). I set the initial value of the capital stock equal to the Bureau of Economic Analysis (BEA) value reported for 1946. Since by assumption the production function (2) features constant returns to scale, the marginal product of capital can be estimated from

$$
M P K_{t}=\alpha \frac{Y_{t}}{K_{t}}
$$

Inherent in $M P K_{t}$ is a technology shock and labor. By making use of the constant return to scale assumption, I do not need to estimate separately the technology shock and work with labor data. In contrast, Cochrane (1991) assumes a constant marginal product of capital and therefore ignores any influences coming from the technology shocks and labor.

\section{$2.3 \quad$ Investment Returns}

Investment returns depend on the capital share $\alpha$, depreciation rate $\delta$, and the adjustment cost parameter $\xi$. The goal of this section is to find a set reasonable parameter values so that the first and second moments of real investment returns match the first and second moments of real stock returns - as predicted by the Q-theory. Generally, I find that investment returns are sensitive to the capital share $\alpha$ and adjustment cost parameter $\xi$ but insensitive to the 
depreciation parameter $\delta$ which I set to the common quarterly value of $2.5 \% \cdot{ }^{10}$

Table 1 reports the annualized first and second moments of investment returns computed for gross investment (Panel A and B), residential (Panel C) and nonresidential investment (Panel D). In Panel A and B, the gross investment return is computed with a capital share of $\alpha=0.2$ and $\alpha=0.3$, respectively. Nonresidential investment returns (Panel C) and residential investment returns (Panel D) are both computed with a capital of $\alpha=0.1$. The last column is the annualized real return of the quarterly value-weighted CRSP index. I exclude data prior to 1955 since the estimated investment return time series are extremely volatile.

For gross investment returns (Panel A and B), two effects are noticeable: First, the mean level of investment returns increases with the capital share $\alpha$. A higher capital share implies a higher marginal product of capital via (10) which in turn determines the mean level of investment returns since $q$ is 1 in the long-run. Second, the adjustment cost parameter $\xi$ affects mainly the investment return volatility. Specifically, the investment return volatility increases with the curvature of the adjustment cost function $\xi$. As a result, the parameter choice of $\alpha=0.2$ and $\xi=0.55$ results in an annualized mean investment return of $7.89 \%$ and standard deviation of $17.19 \%$ compared with the mean CRSP return of $7.86 \%$ and standard deviation of $17.14 \%$. Hence, there exists a realistic parameter set such that the first and second moments of investment returns equal the ones of stock returns - supporting the Q-theory.

To match the mean stock return, I lower the capital share to $\alpha=0.1$ for nonresidential (Panel C) and residential investment returns (Panel D). Otherwise, the mean investment return would be too large because the capital stock in each subcategory is smaller than the capital stock for gross investment resulting in an increase of the marginal product of capital (10) which controls the mean return.

For a capital share $\alpha=0.1$ and adjustment cost parameter $\xi=0.45$, the mean nonresidential investment return and stock return are almost identical (both are around 7\%); however, the standard deviation of the nonresidential investment return $(10.9 \%)$ is considerably lower than the standard deviation of stock returns (17.1\%). By lowering the adjustment cost parameter to $\xi=0.285$, it is possible to match the standard deviation of returns. Yet lowering the

\footnotetext{
${ }^{10}$ See for instance Cooley and Prescott (1995).
} 
adjustment cost parameter increases the mean of nonresidential investment returns to $11.7 \%$. In the case of residential investment with $\alpha=0.1$ and $\xi=0.55$, the standard deviation of investment and stock returns match perfectly. Yet the mean residential investment return $(9.1 \%)$ is higher than the mean stock return $(7.9 \%)$. As before, it is possible to match the mean returns which comes at the cost of creating a wedge between the second moments.

Cochrane (1991) is only able to match the mean of gross investment returns and stock returns. The standard deviation of investment returns is roughly half the standard deviation of stock returns. The fact that I can match first and second moments whereas Cochrane (1991) only matches the first moment is the result of the adjustment cost function. In the specification of Cochrane (1991), the elasticity of the investment-capital ratio is fixed at two whereas here the adjustment cost parameter $\xi$ affects the elasticity and thus the concavity of the function.

In the following, I focus on gross investment returns based on $\alpha=0.2$ and $\xi=0.55$, nonresidential investment returns based on $\alpha=0.1$ and $\xi=0.45$, and residential investment returns based on $\alpha=0.1$ and $\xi=0.55$ because these parameter choices give the best fit in terms of matching the first and second moments of investment and stock returns.

In Figure 1, I plot the annual gross investment return, nonresidential, and residential investment return, respectively. The solid blue line in each figure is the annual real CRSP return and the dashed black line the investment return. Especially for gross investment returns, it is visible that the volatility prior to 1955 is fairly large. Importantly, gross investment returns and nonresidential investment returns seem to lag stock returns. This feature of the data contrasts with the Q-theory and is further analyzed in the next section.

\subsection{Correlation of Investment Returns and Stock Returns}

The last row of each panel of Table 1 presents the contemporaneous correlation of quarterly investment and stock returns, $\rho=\operatorname{Corr}\left(R_{t}^{E}, R_{t}^{I}\right)$. As shown above, the production-based asset pricing model implies that investment returns and stock returns have to be identical state by state. Hence, all moments have to be equal and, more importantly, the two time series have to be perfectly positively correlated. 
For gross investment returns, I find that even though the first and second moments of investment and stock returns almost perfectly match, they are contemporaneously uncorrelated, invalidating the model, $\rho=-4.10 \%$. The result is even stronger for nonresidential investment returns where the contemporaneous correlation is negative, $\rho=-8.95 \%$. Yet residential investment returns are positively correlated with stock returns, $\rho=18.19$.

In Table 2, I report the correlation of real stock returns (CRSP value-weighted) with gross investment returns, nonresidential investment returns, and residential investment returns at $k$ leads and lags, i.e., $\rho_{k}=\operatorname{Corr}\left(R_{t}^{E}, R_{t+k}^{I}\right)$. The t-statistic of the null hypothesis of zero correlation is reported in parenthesis below the estimate.

Even though the returns are contemporaneously uncorrelated, gross investment and stock returns have a correlation of almost $34 \%$ when gross investment returns are shifted by half a year forward. The correlation of real stock returns with gross investment returns is significant at the $5 \%$ level at 1 to 3 quarters leads. Thus, gross investment returns lag stock returns. The lag of nonresidential investment returns is even more pronounced (second column). The correlation pattern is humped shaped indicating that stock returns have a prolonged effect on nonresidential investment. The correlation peaks at $31 \%$ after shifting investment returns half a year forward. The correlation of real stock returns with nonresidential investment returns is significant at the $5 \%$ level at 2 to 4 quarters lag. Residential investment returns behave differently (third column). They are contemporaneously positively and at the $5 \%$ level significantly correlated. Residential investment returns lag stock returns by only one quarter, $\rho_{1}=41 \%$. The correlation of real stock returns with residential investment returns is significant at the $5 \%$ level at 1 and 2 quarters lag.

Contrary to this paper, Cochrane (1991) finds evidence in favor of the Q-theory based on investment returns. He reports a contemporaneous correlation of $24.1 \%$ between investment returns and stock returns. His result is based on three assumptions. First, he studies only gross investment returns. Gross investment is the sum of residential and nonresidential investment. Yet both investment return series behave differently over the business cycle. Whereas residential investment returns are positively correlated with stock returns, nonresi- 
dential investment returns are negatively correlated. His finding is confounding both effects. Moreover, it is sensible to focuses on nonresidential investment because "excluding residential investment is arguably more appropriate for relating investment and stock returns, because most of the residential capital stock is not traded on equity markets" (Lamont (2000) p. 2729). Second, Cochrane (1991) assumes a constant marginal product of capital over time and thereby ignores any influence coming from labor or changes in productivity. Third, he shifts stock returns by a half quarter so that they go from center to center of each quarter. His reasoning for the adjustment is that investment is a quarterly aggregate and stock prices are point to point. Following Lamont (2000), I do not make this adjustment because the correlation pattern between investment and stock returns cannot be resolved by this simple shift.

\subsection{Investment Growth and Stock Returns}

What drives the correlation pattern between investment returns and stock returns? To this end, I report the correlation of real equity returns (CRSP value-weighted) with log gross investment growth, log nonresidential investment growth, and log residential investment growth

at $k$ leads and lags, i.e., $\rho_{k}=\operatorname{Corr}\left(R_{t}^{E}, \Delta \log I_{t+k}\right)$, in Table 3. The t-statistic of the null hypothesis of zero correlation is reported in parenthesis below the estimate.

One of the main puzzles in the investment literature is the negative contemporaneous correlation between gross investment growth and stock price changes (first column) because it contradicts the Q-theory of investment. A decline in expected returns raises marginal Q and as a result investment should increase. At the same time, stock prices increase due to lower expected returns. Hence, investment and stock prices should be contemporaneously positively correlated. Yet empirically, the contemporaneous correlation is negative, contradicting the Q theory.

The contemporaneous negative comovement is even stronger for firm (nonresidential) investment (second column). Lamont (2000) summarizes the puzzle with "The significant negative contemporaneous covariation is particularly puzzling since it seems to suggest that firms perversely cut investment when stock prices go up". Even though the contemporane- 
ous correlation is negative, stock returns are positively correlated with future gross as well as nonresidential investment growth. Thus, the impact of high stock returns leads to positive investment growth for a prolonged period. The highest correlation between future gross investment growth and stock returns occurs at half a year lag, $\rho_{2}=34.2 \%$. Another important feature of gross as well as nonresidential investment growth is the negative correlation with future stock returns, i.e., $\operatorname{Corr}\left(R_{t}^{E}, \Delta \log I_{t-k}\right)<0$. Thus, high gross and nonresidential investment growth predict low stock returns. The correlation pattern between residential investment growth and stock returns is very different (third column). The contemporaneous correlation is positive and, therefore, accords with the Q-theory. The correlation peaks with one quarter lag at $41.2 \%$.

As in the previous section, it is important to differentiate between nonresidential and residential investment because they behave very differently. Moreover, the correlation between investment returns and stock returns (Table 2) is similar to the correlation between investment growth with stock returns (Table 3). Thus, most of the variation of Q-theory investment returns is driven by investment growth.

\section{Model}

The goal of the model is to explain the correlation pattern between Q-theory investment returns and stock returns and the correlation pattern between investment growth rates and stock returns. To this end, I solve a stochastic general equilibrium with production where capital requires time-to-build. The model is similar to Kydland and Prescott (1982) and Christiano and Todd (1996); yet, these authors have not examined the asset pricing implication of time-to-build.

Since the model is a standard production, I focus on the nonresidential investment in line with previous research such as Cooley and Prescott (1995). Nonresidential investment is mainly firm investment, which is captured by the model, whereas residential investment is

mainly housing expenditures by households. In a recent paper, Gomme, Kydland, and Rupert (2001) explain the joint dynamics of residential and nonresidential investment in a model with 
home production.

\subsection{Household}

The representative household maximizes expected lifetime utility over consumption

$$
\max _{\left\{C_{t}, s_{t}, B_{t}\right\}_{t=0}^{\infty}} \mathbb{E}_{0}\left[\sum_{t=0}^{\infty} \beta^{t} u\left(C_{t}\right)\right]
$$

where $\beta \in(0,1)$ denotes the individual discount rate, $C_{t}$ consumption, and $u$ a time-separable

utility function. Since the goal of the model is not to solve the equity premium, I assume power utility

$$
u\left(C_{t}\right)=\frac{1}{1-\gamma} C_{t}^{1-\gamma}
$$

where $\gamma$ is the coefficient of relative risk aversion. The household can buy a risky claim on the firm's dividend stream and a risk-free bond $B_{t}$ such that the time $t$ budget constraint reads

$$
C_{t}+s_{t} P_{t}+B_{t} \leq s_{t-1}\left(P_{t}+D_{t}\right)+R_{f t} B_{t-1}+l_{t} N_{t}
$$

where $s_{t}$ is the fraction of the firm owned by the household, $P_{t}$ the stock price, $D_{t}$ the dividend payment, $l_{t}$ the wage rate, and $N_{t}$ the amount of time working. In equilibrium, the representative household has to hold all shares, i.e., $s_{t}=1$ at all times.

\section{$3.2 \quad$ Firm}

Firms own the economy's real capital and decide about investments. As is Section 2.1, their objective is to maximize expected firm value $P_{t}$ by making optimal real investment decisions $X_{t}$ :

$$
P_{t}=\max _{\left\{X_{t+s}\right\}_{s=1}^{\infty}} \mathbb{E}_{t}\left[\sum_{s=1}^{\infty} \frac{\Lambda_{t+s}}{\Lambda_{t}} D_{t+s}\right] \quad D_{t}=Y_{t}-I_{t}-l_{t} N_{t}
$$

where $\Lambda_{t}$ denotes the pricing kernel and $D_{t}$ the dividend payment to the stock holder. Dividends are defined as the residual payment of output after subtracting investment expenditures $I_{t}$ and labor $\operatorname{costs} l_{t} N_{t}$. Output is determined by a Cobb-Douglas production function $F$

$$
Y_{t}=e^{z_{t}} F\left(K_{t}, N_{t}\right) \quad F\left(K_{t}, N_{t}\right)=K_{t}^{\alpha} N_{t}^{1-\alpha}
$$


where $K_{t}$ denotes capital, $z_{t}$ an exogenous technology shock, and $\alpha$ the capital share of production. Output is subject to a technology shock $Z_{t}$ which follows an $\operatorname{AR}(1)$ processes

$$
z_{t}=\rho z_{t-1}+\varepsilon_{t}
$$

with persistence $\rho$ and normal distributed innovation $\varepsilon_{t} \sim \mathcal{N}(0, \sigma)$.

A time-to-build model captures two important aspects of real life investment projects: (1) a lag between the investment decision and when the new asset becomes productive and (2) a lag the between the investment decision and when the firm incurs the costs for the new project. To capture these aspects, the model has to contain one additional state-variable relative to the standard neoclassical model of Section 2.1. Specifically, $X_{t}$ denotes the size of a new project initiated at date $t$ whereas $I_{t}$ denotes the investment expenditures at date $t$.

In order to capture the lag between the investment decision and when the new projects becomes available, the law of motion for capital has to be adjusted. To keep the model as simple as possible, I assume two periods time-to-build. Consequently, the current investment decision $X_{t}$ becomes productive two periods later and the motion for capital is

$$
K_{t+2}=(1-\delta) K_{t+1}+X_{t}
$$

In contrast, in the standard neoclassical model of Section 2.1 the investment decision increases next period's capital stock.

The second aspect of time-to-build, the lag between the investment decision and when the firm incurs the costs for the new project, gives rise to a new law of motion for investment expenditures. A natural assumption is that firms incur costs for all ongoing projects. Thus, investment expenditures at date $t, I_{t}$, are a weighted average of the past two investment decisions

$$
I_{t}=w X_{t}+(1-w) X_{t-1}
$$

where the weight $w$ determines the timing of the costs. There are two extreme cases: When $w=1$, firms incur the full cost when they make the investment decision; whereas firms incur the cost a period later when $w=0$. In the case $0<w<1$, the firm incurs some costs in 
each period. The specification of the the investment costs (16) follows Kydland and Prescott (1982) and Christiano and Todd (1996).

Previous papers have assumed four quarters time-to-build. Since the asset pricing implications are driven by the timing of the costs, I have simplified the standard time-to-build model to two quarters. As a result, only a single parameter, namely $w$, determines the timing of the investment costs. With four period time-to-build, there are three free parameters and the implications would be less clear-cut.

\subsection{Equilibrium Returns}

The household's first order condition ${ }^{11}$ with respect to $s_{t}$ gives the standard Lucas Euler equation for stock returns

$$
u^{\prime}\left(C_{t}\right)=\beta \mathbb{E}_{t}\left[u^{\prime}\left(C_{t+1}\right) R_{t+1}^{E}\right]
$$

where

$$
R_{t+1}^{E}=\frac{P_{t+1}+D_{t+1}}{P_{t}}
$$

denotes the return on equity. Note that in equilibrium $N_{t}=1$ since labor does not enter the utility function. The price of the consumption numeraire is $\Lambda_{t}=u^{\prime}\left(C_{t}\right)$ and thus the pricing kernel is

$$
M_{t+1}=\beta \frac{\Lambda_{t+1}}{\Lambda_{t}}
$$

The risk-free rate is given by $1 / R_{t}^{f}=\mathbb{E}_{t} M_{t+1}$.

Since time-to-build is an investment friction, a Tobin's $\mathrm{Q}$ interpretation arises. Let $\Gamma_{t}$ be the Lagrange multiplier on (15). Marginal $\mathrm{Q}$ is the ratio of the marginal value of an additional unit of capital, $\Gamma_{t}$, divided by the price of a unit of capital, $\Lambda_{t}$. Dividing the first order condition of (13) with respect to $X_{t}$ by $\Lambda_{t}$ yields marginal $\mathrm{Q}$, denoted by $q_{t},{ }^{12}$

$$
q_{t}=\frac{\Gamma_{t}}{\Lambda_{t}}=w+(1-w) \beta \mathbb{E}_{t}\left[\frac{\Lambda_{t+1}}{\Lambda_{t}}\right]
$$

\footnotetext{
${ }^{11} \mathrm{~A}$ competitive rational expectations equilibrium is a sequence of allocations $\left\{C_{t}, K_{t}\right\}_{t=0}^{\infty}$ and a price system $\left\{\Lambda_{t}, P_{t}\right\}_{t=0}^{\infty}$ such that: ( $i$ ) given the price system, the representative household maximizes (11) s.t. (12); (ii) given the price system, the representative firm maximizes (13) s.t. (15); (iii) the good market clears: $Y_{t}=C_{t}+I_{t} ;(4)$ the stock market clears $s_{t}=1$. By Walras' law, the labor market clears as well.

${ }^{12}$ See the Appendix for a detailed derivation.
} 
Consequently, marginal $\mathrm{Q}$ is a weighted average of the investment costs where the weight is given by the risk-free rate. Marginal Q is time-varying because parts of the investment costs are incurred in the future and these sure costs have to be discounted at the risk-free rate.

The solution to the firm's optimization problem can be characterized by the firm's Euler equation

$$
\Lambda_{t}=\beta \mathbb{E}_{t}\left[\Lambda_{t+1} R_{t+1}^{I}\right]
$$

where the time-to-build investment return is defined by

$$
R_{t+1}^{I}=\frac{\beta \mathbb{E}_{t+1}\left[\frac{\Lambda_{t+2}}{\Lambda_{t+1}} e^{z_{t+2}} F_{1}\left(K_{t+2}, N_{t+2}\right)\right]+q_{t+1}(1-\delta)}{q_{t}}
$$

The investment return $R_{t+1}^{I}$ defines the firm's intertemporal tradeoff of investing one more unit of capital. It is the ratio of tomorrow's marginal benefits of investing one additional unit of capital divided by today's marginal costs. Since the marginal product of an additional unit of capital occurs in 2 periods and is thus risky, it has to be discounted using the pricing kernel.

Another important implication is that the time-to-build investment return (19) differs from the adjustment cost investment return (7). Generally, investment returns are model specific whereas stock returns are not. Moreover, I can compute Q-theory based investment returns on simulated data of the time-to-build model and compare them with stock returns. Importantly, the Q-theory based investment return are misspecified since they do not reflect the firm's true intertemporal tradeoff.

Due to constant returns to scale of the production function (14), firm value $P_{t}$ can be solved analytically and is given by

$$
P_{t}=q_{t} K_{t+2}-(1-w) X_{t} \mathbb{E}_{t}\left[M_{t+1}\right]+\mathbb{E}_{t}\left[M_{t} e^{z_{t+1}} F\left(K_{t+1}, N_{t+1}\right)\right]
$$

Under time-to-build, the equivalence of marginal and average $\mathrm{Q}$ breaks down and hence leads to a deviation of investment and stock returns. To see this note that average $\mathrm{Q}$ is defined as

$$
Q_{t}=\frac{P_{t}}{K_{t+2}}
$$


Substituting (20) into (21) and comparing the resulting expression with (18), it follows that marginal Q deviates from average Q, i.e., $Q_{t} \neq q_{t}$. Altuğ (1993) first noticed this feature of time-to-build.

The difference between marginal and average $\mathrm{Q}$ arises because firm value (20) reflects not only the value of productive capital $q_{t} K_{t+2}$ but also the value of unfinished investment projects. More specifically, firm value has to be reduced by future investment costs, which surely occur because of past investment decisions. The second term of (20) captures these costs. The third term is discounted future profits due to past investment decisions.

\subsection{Calibration}

Table 4 summarizes the parameters' choice. These values are similar to Cooley and Prescott (1995) and correspond to quarterly frequency. The household discounts future consumption at an annual rate of 3 percent implying $\beta=1.03^{-1 / 4}$. I set the coefficient of relative risk aversion equal to 5 so that the results are not driven by extreme risk aversion. The capital share of production is $\alpha=0.36$. The quarterly depreciation rate of capital, $\delta$, equals 0.025 implying 10\% annual depreciation. The technology shock is mean zero with autocorrelation $\rho$ of 0.95 and standard deviation $\sigma$ of 0.007 percent. I solve the model with a second order perturbation around the simulated mean of the model, following Collard and Juillard (2001).

\section{Results}

Since the asset pricing implications are driven by the timing of the investment costs, I present three model versions with different timing. In Model A, I assume that the total investment costs are incurred in the period after the investment decision, i.e., $w=0$. Thus, the firm decides to invest in the future but does not incur any costs in the current period. Following Kydland and Prescott (1982), in Model B the investment costs are spread evenly over the two periods, i.e., $w=0.5$. The specification of Kydland and Prescott (1982) results in an oscillating investment decision because firms thereby smooth the average investment costs. In Model C, I enhance the two period time-to-build with continuous adjustment costs. Consistent with the empirical investment literature, I assume that some investment costs are incurred 
in the current period, i.e., $w=0.2$. This specification results in a very realistic correlation pattern between investment growth and stock returns.

\subsection{Model A: $w=0$}

To understand the economics of the model, I analyze its impulse response functions. Figure 2 depicts the impulse response functions of consumption $C_{t}$, risk-free rate $R_{t}^{f}$, investment decision $X_{t}$ and investment expenditures $I_{t}$, realized stock return $R_{t}^{E}$ and expected stock return $\mathbb{E}_{t}\left[R_{t+1}^{E}\right]$ after a one percent technology shock in period one.

After a positive shock, the investment decision rises because the firm wants to take advantage of higher productivity. The investment expenditures have the same impulse response pattern as the investment decision but they lag one period due to time-to-build. The aggregate resource constraint implies that consumption has to absorb the positive shock because investment expenditures cannot. Consequently, consumption is initially high but then reverts back.

The asset pricing implications of the time-to-build friction are driven by two effects which, importantly, work in opposite direction. First, time-to-build affects the risk-free rate and, second, the risk premium of the firm. In contrast to standard continuous adjustment costs, these two channels arise since time-to-build captures two aspects of real life investment projects: (1) a lag between the investment decision and when the new asset becomes productive and (2) a lag the between the investment decision and when the firm incurs the costs for the new project. The first aspect mainly affects the risk premium and the second one the risk-free rate.

In contrast to the traditional exchange economy, the supply of capital is endogenous in a production economy and its elasticity determines risk premia. Time-to-build affects the elasticity of capital since investment decisions increase the capital stock with a lag. Consequently, the capital stock is fully inelastic in the short-term after a positive shock and excess returns are high. High expected excess returns lower prices and therefore lead to low current realized returns. Since all investment costs are incurred in the period after the shock, both realized returns and investment expenditures are low in the period of the shock. This mechanism by 
itself would lead to a positive correlation between returns and investments, contradicting the empirical evidence.

However, time-to-build also affects the risk-free rate. The second effect of time-to-build on the risk-free rate arises since consumption absorbs the positive shock, but falls afterwards. This negative expected consumption growth necessitates a low risk-free rate because the household would like to sell the bond to smooth consumption over time. Yet the bond is in zero net supply and as a result the risk-free rate falls to make the investment into the bond less attractive. The low risk-free rate increases the stock price and thus realized returns. Importantly, the effects of the risk-free rate and the risk premium on current realized returns work in opposite directions. I find, however, that the risk-free rate effect dominates the risk premium effect resulting in a high realized stock return initially when investment expenditures are low. As a result, realized returns and investment growth are negatively correlated, as in the data.

The above intuition is summarized in Table 7 (Model A) which reports the correlation of stock returns and investment growth, $\operatorname{Corr}\left(R_{t}^{E}, \Delta \log I_{t+k}\right)$, based on simulating the model. The first column of Table 7 (Data) is the correlation between the return of the value-weighted CRSP index and nonresidential investment growth. Consistent with the data, stock returns and investment growth are negatively correlated contemporaneously and positively correlated with a lag. Missing, however, is the prolonged positive effect.

Another goal of the model is to replicate the correlation pattern between stock returns and Q-theory investment returns. Table 6 reports the correlation between stock returns $R_{t}^{E}$ and misspecified investment returns $R_{t}^{I}$ based on the adjustment costs model (7). The adjustment cost parameter $\xi$ is set to same value used in the empirical section, $\xi=0.45 .{ }^{13}$ The Q-theory based investment returns are misspecified on simulated data since investment returns depend on the investment frictions. The true investment return underlying this economy is given by (19).

In column labeled Model A, misspecified Q-theory investment returns are contemporaneously negatively correlated with stock returns and positively correlated at one lag, similar

\footnotetext{
${ }^{13}$ The results of this table are robust with respect to variation in the adjustment cost function parameter $\xi$.
} 
to the data. The response of Q-theory investment returns is delayed by one period because time-to-build delays the response of investment expenditures which are the main determinants of Q-theory investment returns.

Even though the expected return is low on impact of the shock, the risk premium is positive. Since a positive technology shock cannot be absorbed by investments, prices must change. Therefore, asset prices are volatile and sensitive to to market-wide uncertainty, i.e., returns have higher systematic risk. The stock holder therefore receives a compensation for the investment risk in terms of a positive expected excess return, which can be seen in Table 5. Specifically, even though the household has power utility, the model generates almost a one percent excess return.

In the standard RBC model, stock and investment returns are identical state by state. To generate a high stock return in such a model, the marginal rate of transformation of capital, i.e. the investment return, has to be very volatile as well. This close tie between stock and investment returns is broken in a model with time-to-build because average $\mathrm{Q}$ diverge from marginal Q. Here, investment returns can remain smooth but stock returns are volatile. Further, the model generates a high standard deviation of the stock return, alleviating the excess volatility puzzle.

\subsection{Model B: $w=0.5$}

Following Kydland and Prescott (1982), the investment costs are now spread evenly over the two periods, i.e. $w=0.5$. When firms incur some of the investment cost in the same period as the investment decision, the dynamics are more complex. Figure 3 depicts the impulse response functions of consumption $C_{t}$, risk-free rate $R_{t}^{f}$, investment decision $X_{t}$ and investment expenditures $I_{t}$, realized stock return $R_{t}^{E}$ and expected stock return $\mathbb{E}_{t}\left[R_{t+1}^{E}\right]$ after a one percent technology shock in period one.

A striking feature of these impulse response function is the oscillation. This pattern is not unique to two periods of time-to-build, but also apparent in the graphs reported by Christiano and Todd (1996) with 4 periods time-to-build. The rationale behind the dynamics is the objective of a smooth consumption stream for the household, which necessitates a smooth 
dividend stream. Since the firm cannot initially smooth output because of time-to-build of the capital stock, it wants to dampen the investment costs.

As the technology shock is highest on impact, the firm wants to incur most of the costs at time 1 and thus the investment decision is above the steady state. In the second period, the firm decides to invest only the steady state level $\bar{X}$. As a result, the investment costs are smooth

$$
I_{1}=0.5 X_{1}+0.5 \bar{X}=I_{2}=0.5 \bar{X}+0.5 X_{1}
$$

Hence, oscillating between large and small investment projects is optimal.

Following the same reasoning as above, the negative expected consumption growth rate after the initial shock results in a low risk-free rate. Since consumption growth oscillates after the shock, the risk-free rate oscillates as well. The expected stock return is again low on impact of the shock, which is induced by the low risk-free rate. This implies that the risk premium component does not offset the negative risk-free rate effect.

The low expected return causes a high stock price and high realized return but, in the model specification with $w=0.5$, the investment costs are high as well. As a result, investment growth and stock return are positively correlated, contradicting empirical facts. Table 7 and 2 present the correlation between investment growth and stock returns and the correlation between misspecified investment returns and stock returns, respectively (column Model B). It is apparent, that the standard time-to-build specification generates an unrealistic correlation pattern between investment growth and stock returns and investment returns and stock returns. Since firms incur half of the investment costs in the initial period, stock returns are positively correlated with investment growth and Q-theory investment returns.

The second column of Table 5 summarizes the moments of data generated by this specification. Most importantly, the mean excess return with $w=0.5$ is lower than with $w=0$. The reason is that with $w=0.5$ half of the investment costs are already incurred in the initial period of the project. Consequently, consumption does not have to absorb the entire shock, but investments expenditures can adjust as well. This effect reduces the volatility of consumption growth and therefore the equity premium. 
Concluding, time-to-build does not necessarily imply a negative correlation between investment growth and stock returns. The timing of the investment costs are the crucial determinant of the asset pricing implications.

\subsection{Model C: Time-to-Build with Adjustment Costs}

As soon as firms incur some of the costs in the initial period, it is optimal for the firm to oscillate between high and low investment decisions. To remedy this feature of the model, I enhance the time-to-build specification with continuous adjustment costs. Q-theory based investment models assume continuous adjustment costs in the investment rate, $I_{t} / K_{t}$, so that firms are penalized for quick capital adjustment. This specification, however, does not solve the oscillation because the investment costs are fairly smooth. The adjustment costs employed here penalize the firm for switching between high and low investment decisions. The adjustment costs are therefore a function of the investment decision growth rate $X_{t} / X_{t-1}$. This adjustment cost function induces more realistic firm behavior. Importantly, this specification is not rejected by the empirical test in this paper. The standard continuous adjustment costs in the investment rate imply the equivalence of marginal and average Q. This implication does not hold when the adjustment costs are based on lagged variables such as $X_{t-1}$ which is the case here.

Adjustment costs reduce the two periods ahead capital stock and thus the new law of motion for capital is

$$
K_{t+2}=(1-\delta) K_{t+1}+\left(1-S\left(\frac{X_{t}}{X_{t-1}}\right)\right) X_{t}
$$

where $S$ is a concave function in $X_{t} / X_{t-1}$

$$
S(x)=\frac{\chi}{2}\left(e^{x-1}+e^{-(x-1)}-2\right)
$$

A similar specification has been used by Christiano, Eichenbaum, and Evans (2005). Since it is unrealistic to assume that no investment costs are due in the initial period, I assume $w=0.2$. Further, I set the adjustment costs parameter $\chi=1$.

As a result of the adjustment costs, the impulse response functions of the model are smooth; see Figure 4. The impulse responses of the investment decision and investment costs 
are hump-shaped because the firm would otherwise incur high adjustment costs. As before, the expected stock return and risk-free rate are low on impact of the shock, resulting in a high realized return. In Table 7 (Model C), the correlation between investment growth and stock returns is depicted. This table shows that the model is able to replicate three features of investment and stock market data: First, investment growth is negatively correlated with future stock returns; second, the contemporaneous correlation between investment growth and stock return is negative; and third, stock returns are positively correlated with future investment growth. Table 2 (Model C) shows that the correlation between stock returns and Q-theory investment returns also matches the observed pattern in the data.

A drawback of this model is that consumption growth is too volatile, causing a high standard deviation of the risk-free rate. The third column of Table 5 summarizes the moments of the model. The model further generates a considerable standard deviation of the stock return and a small excess return which is larger than in the standard time-to-build with $w=0.5$.

\section{Conclusion}

The findings in this paper support the importance of time-to-build in order to jointly explain stock market and investment data. At the aggregate level, investment growth and equity returns are negatively correlated. This empirical fact contradicts the Q-theory of investment and has therefore been interpreted as evidence for irrational markets. However, a general equilibrium model, in which investment projects are not completed instantaneously, can explain this negative correlation, because the model endogenously generates dynamics in the risk premium and risk-free rate. These dynamics are crucial to replicate the negative correlation between investments and returns.

A time-to-build model captures two important aspects of real life investment projects: (1) a lag between the investment decision and when the new asset becomes productive and (2) a lag the between the investment decision and when the firm incurs the costs for the new project. 
Time-to-build induces risk dynamics because it affects the elasticity of capital. A partial equilibrium model would therefore predict high expected returns at the investment date. This effect reduces current prices and realized returns. Since investment expenditure are initially low, too, investment growth and returns are positively correlated, which is inconsistent with the data.

In general equilibrium, however, the pricing kernel is endogenous and its dynamics determines the risk-free rate. Since most investment expenditures are due at the end of the project, consumption has to absorb positive shocks and is therefore initially high but falls afterwards. A negative expected consumption growth rate necessitates a low risk-free rate because the agent would like to sell the bond to smooth consumption over time. The low risk-free rate increases current prices and realized returns. After a positive shock, investment growth is initially low, because most expenditures are due in later periods, but realized returns are high. Thus, the model generates a negative correlation between investment growth and return, consistent with the data.

A extension of the two period time-to-build specification with costly adjustment is able to explain three phenomena: First, the negative correlation of investment growth and future stock returns; second, the negative contemporaneous comovement of stock returns and investment growth; and third, the prolonged positive correlation of stock returns and future investment growth. 


\section{References}

Abel, A. B., and J. C. Eberly, 1994, "A Unified Model of Investment Under Uncertainty," American Economic Review, 84, 1369-1384.

Altuğ, S., 1993, "Time-to-Build, Delivery Lags, and the Equilibrium Pricing of Capital Goods," Journal of Money, Credit, and Banking, 25, 301-319.

Baker, M., R. Ruback, and J. Wurgler, 2006, "Behavioral Corporate Finance: A Survey," in The Handbook of Corporate Finance: Empirical Corporate Finance, ed. by E. Eckbo. Elsevier, North Holland.

Baker, M., J. C. Stein, and J. Wurgler, 2003, "When Does the Market Matter? Stock Prices and the Investment of Equity-Dependent Firms," Quarterly Journal of Economics, 118(3), 969-1005.

Bar-Ilan, A., and W. C. Strange, 1996, "Investment Lags," American Economic Review, 86, $610-622$.

Barro, R. J., 1990, "The Stock Market and Investment," Review of Financial Studies, 3, $115-131$.

Berk, J., R. C. Green, and V. Naik, 1999, "Optimal Investment, Growth Options, and Security Returns," Journal of Finance, 54, 1553-1607.

Boldrin, M., L. J. Christiano, and J. D. M. Fisher, 2001, "Habit Persistence, Asset Returns and the Business Cycle," American Economic Review, 91, 149-166.

Carlson, M., A. Fisher, and R. Giammarino, 2004, "Corporate Investment and Asset Price Dynamics: Implications for the Cross-section of Returns," Journal of Finance, 59, 25772603.

— , 2007, "SEOs, Real Options, and Risk Dynamics: Empirical Evidence," Working paper.

Christiano, L., M. Eichenbaum, and C. Evans, 2005, "Nominal Rigidities and the Dynamic Effects of a Shock to Monetary Policy," Forthcoming, Journal of Political Economy.

Christiano, L. J., and J. D. Fisher, 2003, "Stock Market and Investment Goods Prices: Implications for Macroeconomics," NBER working paper 5292.

Christiano, L. J., and R. M. Todd, 1996, "Time to Plan and Aggregate Fluctuations," Federal Reserve Bank of Minneapolis Quarterly Review, 20, 14-27.

Christiano, L. J., and R. J. Vigfusson, 2003, "Maximum Likelihood in the Frequency Domain: The Importance of Time-to-Plan," Journal of Monetary Economics, 50, 789-815. 
Cochrane, J. H., 1991, "Production-Based Asset Pricing and the Link Between Stock Returns and Economic Fluctuations," Journal of Finance, 46, 209-237.

— 1996, "A Cross-Sectional Test of an Investment-Based Asset Pricing Model," Journal of Political Economy, 104(3), 572-621.

Collard, F., and M. Juillard, 2001, "Accuracy of stochastic perturbation methods: The case of asset pricing models," Journal of Economic Dynamics $\&$ Control, 25, 979-999.

Cooley, T. F., and E. C. Prescott, 1995, "Economic Growth and Business Cycles," in Frontiers of Business Cycle Research, ed. by T. F. Cooley. Princeton University Press, Princeton, NJ, pp. $1-38$.

Cooper, I., 2006, "Asset Pricing Implications of Non-Convex Adjustment Costs of Investment," Journal of Finance, 61, 139-170.

Cox, J. C., J. E. Ingersoll, and S. A. Ross, 1985, "An Intertemporal General Equilibrium Model of Asset Prices," Econometrica, 53(2), 363-384.

Danthine, J.-P., and J. B. Donaldson, 2002, "Labor Relation and Asset Returns," Review of Economic Studies, 69, 41-64.

Erickson, T., and T. M. Whited, 2000, "Measurement Error and the Relationship between Investment and q," Journal of Political Economy, 108, 1027-1057.

Farhi, E., and S. Panageas, 2004, "The Real Effects of Stock Market Mispricing at the Aggregate: Theory and Empirical Evidence," Working paper.

Ghemawat, P., 1984, "Capacity Expansion in Titanium Dioxide Industry," Journal of Industrial Economics, 33, 145-166.

Gilchrist, S., and C. P. Himmelberg, 1995, "Evidence on the Role of Cash Flow for Investment," Journal of Monetary Economics, 36, 541-572.

Gilchrist, S., C. P. Himmelberg, and G. Huberman, 2005, "Do stock price bubbles influence corporate investment?," Journal of Monetary Economics, 52(4), 805 - 827.

Gomes, J. F., L. Kogan, and L. Zhang, 2003, "Equilibrium Cross Section of Returns," Journal of Political Economy, 111, 693-732.

Gomes, J. F., A. Yaron, and L. Zhang, 2006, "Asset Pricing Implications of Firms Financing Constraints," Review of Financial Studies, 19, 1321-1356.

Gomme, P., F. E. Kydland, and P. Rupert, 2001, "Home Production Meets Time to Build," Journal of Political Economy, 109(5), 1115-1131. 
Guvenen, F., 2004, "A Parsimonious Macroeconomic Model for Asset Pricing: Habit Formation or Cross-sectional Heterogeneity?," Working paper.

Hall, R., 2001, "The Stock Market and Capital Accumulation," American Economic Review, 91, 1185-1202.

Hayashi, F., 1982, "Tobin's Marginal q and Average q: A Neoclassical Interpretation," Econometrica, 50, 213-224.

Jermann, U. J., 1998, "Asset Pricing in Production Economies," Journal of Monetary Economics, 41, 257-275.

— , 2005, "The Equity Premium Implied by Production," Working paper.

Jorgenson, D. W., and J. A. Stephenson, 1967, "The Time Structure of Investment Behavior in United States Manufacturing, 1947-1960," Review of Economics and Statistics, 49, 16-27.

Koeva, P., 2000, "The Facts About Time-to-Build," IMF Working paper.

—— , 2001, "Time-to-Build and Convex Adjustment Costs," IMF Working paper.

Kogan, L., 2001, "An Equilibrium Model of Irreversible Investment," Journal of Financial Economics, 62, 201-245.

— , 2004, "Asset Prices and Real Investment," Journal of Financial Economics, 73, 411-432.

Kydland, F. E., and E. C. Prescott, 1982, "Time to Build and Aggregate Fluctuations," Econometrica, 50, 1345-1370.

Lamont, O. A., 2000, "Investment Plans and Stock Returns," Journal of Finance, 55, 27192745 .

Lettau, M., 2003, "Inspecting the Mechanism: Closed-form Solutions for Asset Prices in Real Business Cycle Models," Economic Journal, 113, 550-575.

Lettau, M., and S. Ludvigson, 2002, "Time-Varying Risk Premia and the Cost of Capital: An Alternative Implication of the Q Theory of Investment," Journal of Monetary Economics, $49,31-66$.

Li, Q., M. Vassalou, and Y. Xing, 2006, "Sector Investment Growth Rates and the CrossSection of Equity Returns," Journal of Business, 79, 1637-1665.

Liu, L. X. L., T. M. Whited, and L. Zhang, 2007, "Investment-Based Expected Stock Returns," Working paper. 
Majd, S., and R. S. Pindyck, 1987, "Time to Build, Option Value, and Investment Decisions," Journal of Financial Economics, 18, 7-27.

Mayer, T., 1960, "Plant and Equipment Lead Time," Journal of Business, 33, 127-132.

Montgomery, M., 1995a, "Capital Complementarity, Time-To-Build, and the Persistence of Investment Starts," Journal of Macroeconomics, 17, 187-205.

, 1995b, "Time-To-Build Completion Patterns for Nonresidential Structures, 19611991," Economics Letters, 48, 155-163.

Polk, C., and P. Sapienza, 2009, "The Stock Market and Corporate Investment: A Test of Catering Theory," Review of Financial Studies, 22, 187-217.

Restoy, F., and G. M. Rockinger, 1994, "On Stock Returns and Returns on Investment," Journal of Finance, 49, 543-556.

Rouwenhorst, K. G., 1995, "Asset Pricing Implications of Equilibrium Business Cycle Models," in Frontiers of Business Cycle Research, ed. by T. F. Cooley. Princeton University Press, Princeton, NJ, pp. 294-330.

Zhang, L., 2005, "The Value Premium," Journal of Finance, 60, 67-103.

Zhou, C., 2000, "Time-to-Build and Investment," Review of Economics and Statistics, 82, 273-282. 

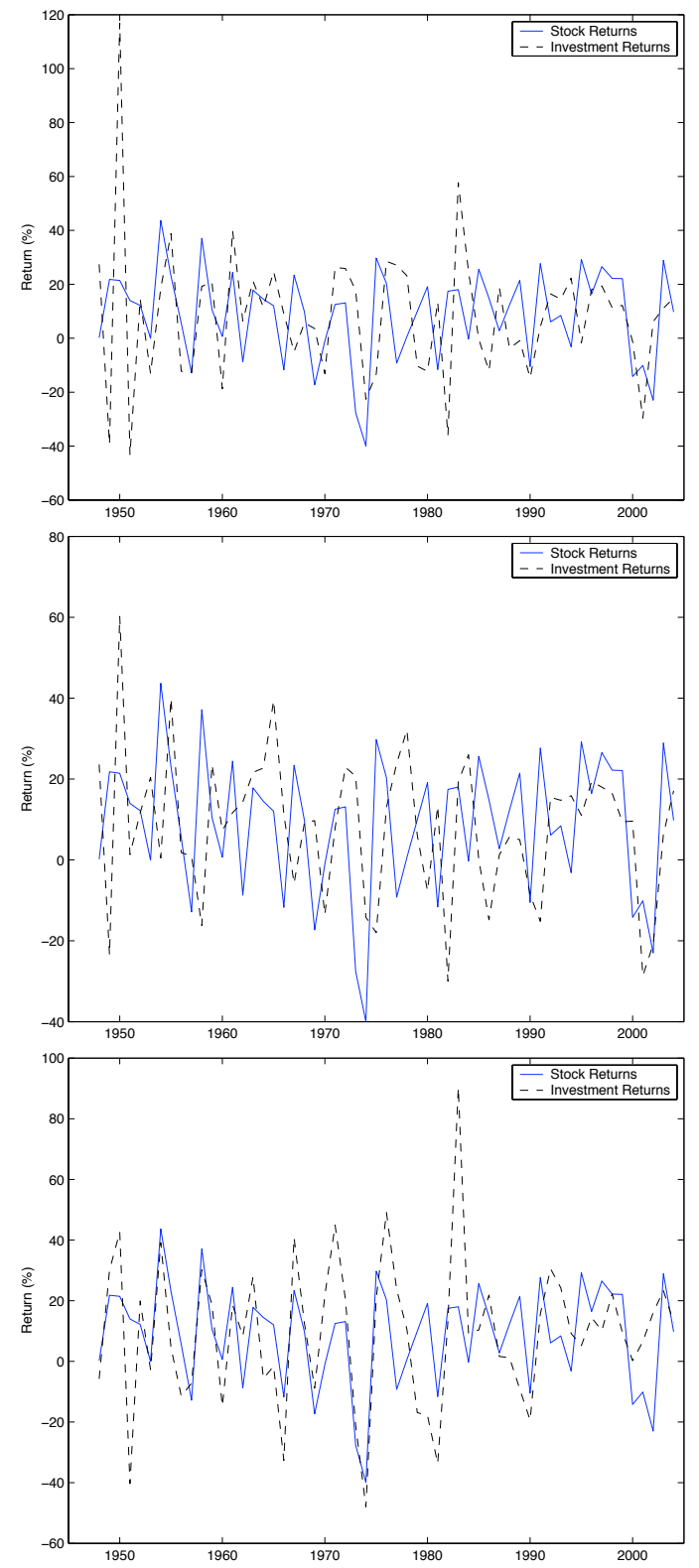

Figure 1: Investment Returns

This figure shows annual investment returns (dashed line) based on private investment, $\alpha=$ $0.2, \xi=0.55$ (top figure), nonresidential fixed investment, $\alpha=0.1, \xi=0.45$ (middle figure), and residential fixed investment, $\alpha=0.1, \xi=0.55$ (bottom figure) and stock returns (solid line) for the period 1947 to 2004. 

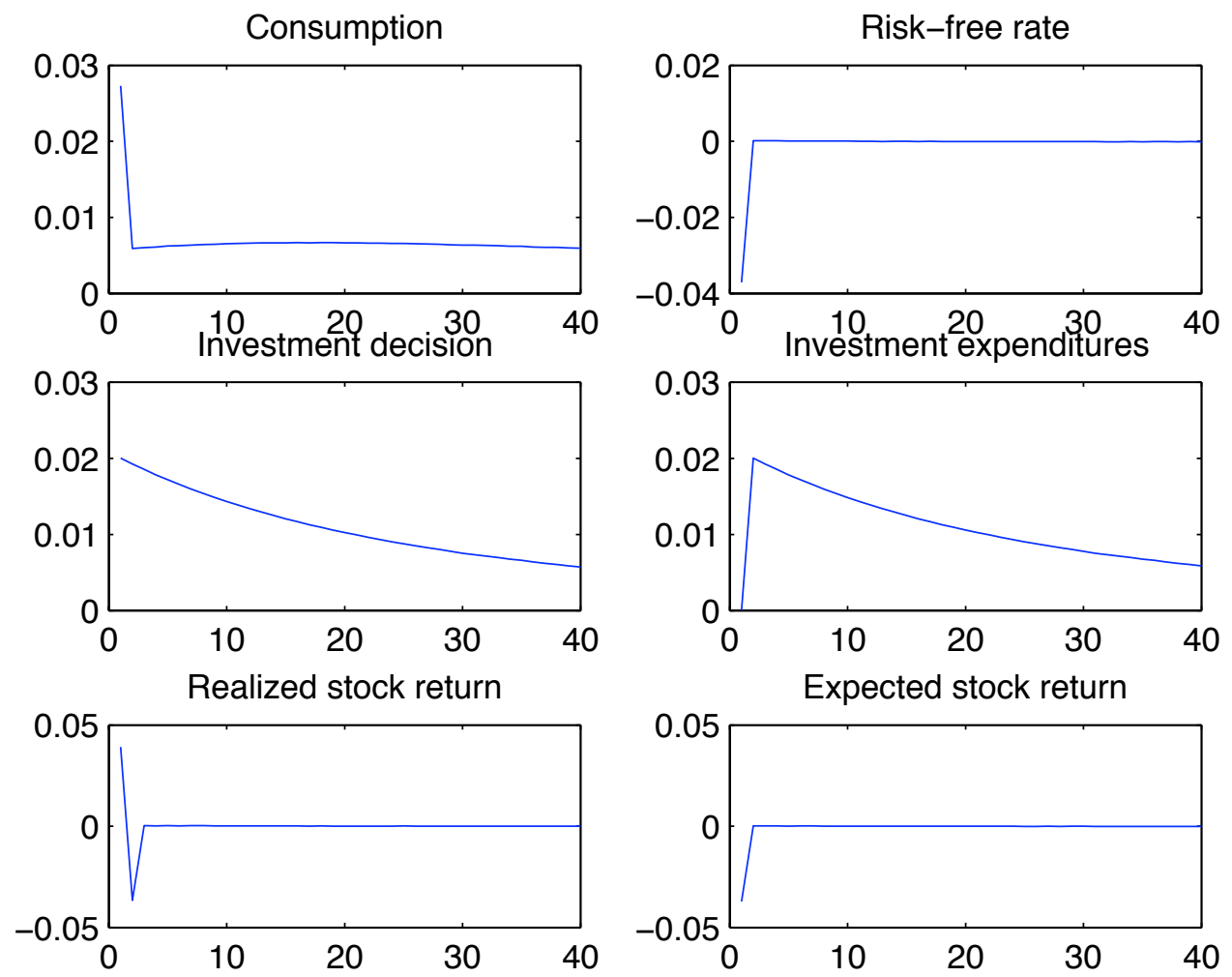

Figure 2: Impulse Response Function

This figure shows the impulse response functions of consumption $C_{t}$, risk-free rate $R_{t}^{f}$, investment decision $X_{t}$, investment expenditures $I_{t}$, realized stock return $R_{t}^{E}$ and expected stock return $\mathbb{E}_{t}\left[R_{t+1}^{E}\right]$ for the time-to-build model with $w=0$. 

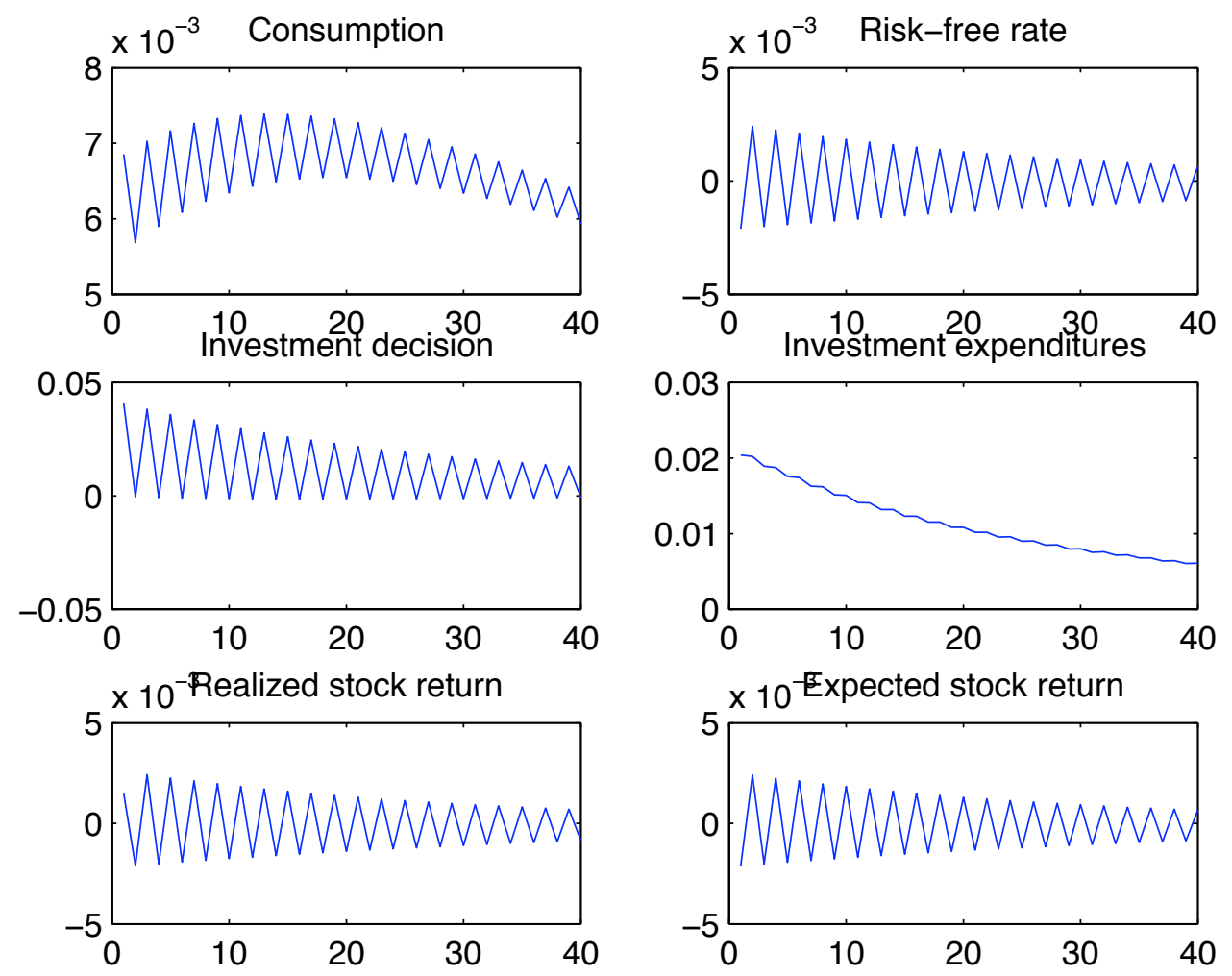

Figure 3: Impulse Response Function

This figure shows the impulse response functions of consumption $C_{t}$, risk-free rate $R_{t}^{f}$, investment decision $X_{t}$, investment expenditures $I_{t}$, realized stock return $R_{t}^{E}$ and expected stock return $\mathbb{E}_{t}\left[R_{t+1}^{E}\right]$ for the time-to-build model with $w=0.5$. 

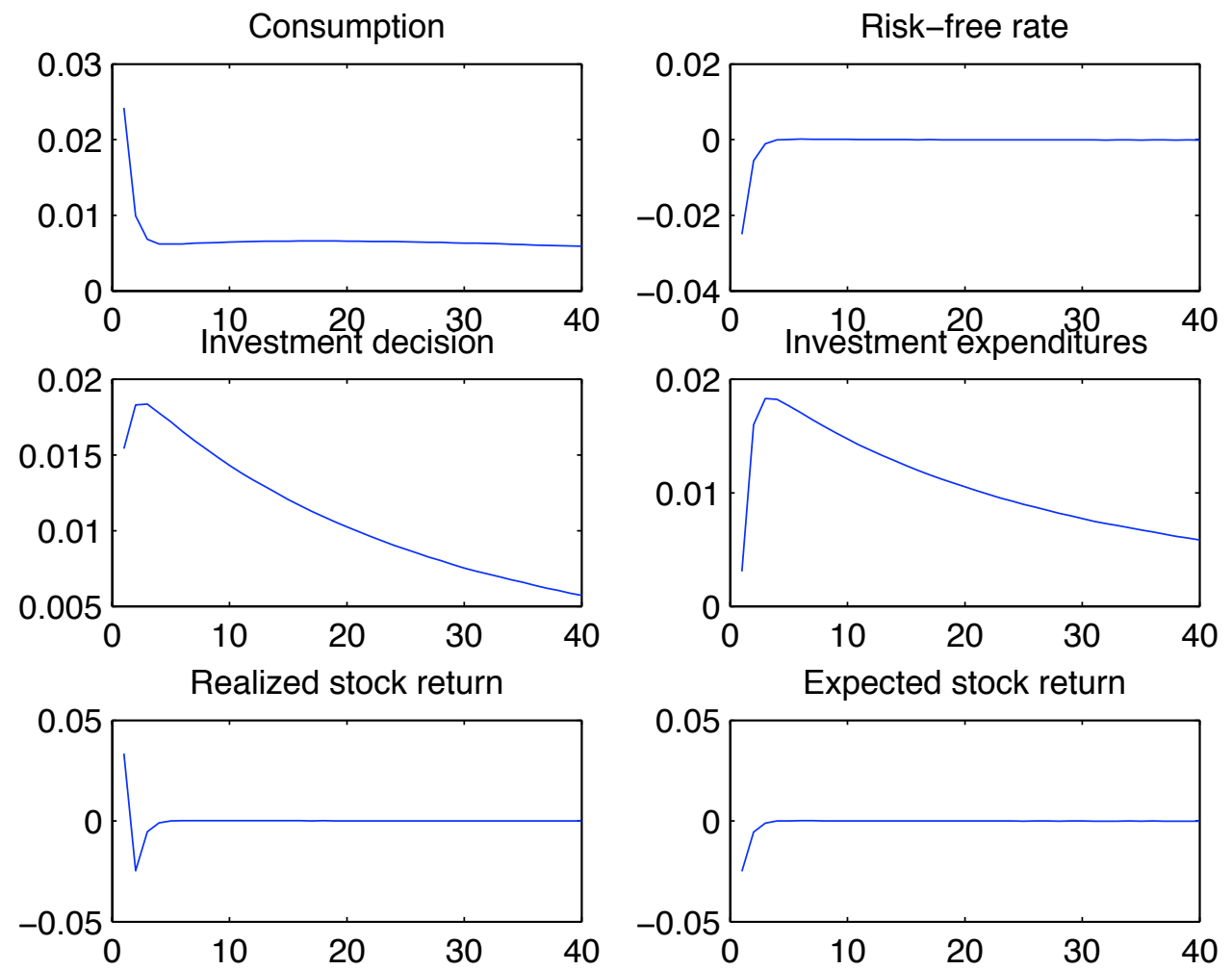

Figure 4: Impulse Response Function

This figure shows the impulse response functions of consumption $C_{t}$, risk-free rate $R_{t}^{f}$, investment decision $X_{t}$, investment expenditures $I_{t}$, realized stock return $R_{t}^{E}$ and expected stock return $\mathbb{E}_{t}\left[R_{t+1}^{E}\right]$ for the adjustment costs enhanced time-to-build model with $\chi=1$ and $w=0.2$. 
Table 1: Investment Returns

This table reports the annualized mean and standard deviation of real investment returns based on real gross private investment (Panel A and B), real private nonresidential (Panel C) and residential fixed investment (Panel D). The last row of each panel is the contemporaneous correlation of investment and stock returns in percent, $\operatorname{Corr}\left(R_{t}^{E}, R_{t}^{I}\right)$. The last column is the annualized mean and standard deviation of the quarterly real return of the CRSP valueweighted index. The sample period is 1955-2004.

\begin{tabular}{ccccc}
\hline \multicolumn{5}{c}{ Panel A: Gross private investment $(\alpha=0.2)$} \\
\hline$\xi$ & 10 & 2 & 0.55 & CRSP \\
\hline Mean & 6.39 & 6.42 & 7.89 & 7.86 \\
Std. Dev. & 1.14 & 4.85 & 17.19 & 17.14 \\
Correlation & -8.53 & -5.30 & -4.10 & \\
\hline \multicolumn{5}{c}{ Panel B: Gross private investment $(\alpha=0.3)$} \\
\hline$\xi$ & 10 & 2 & 0.55 & CRSP \\
\hline Mean & 14.36 & 13.50 & 12.18 & 7.86 \\
Std. Dev. & 1.30 & 4.94 & 17.33 & 17.14 \\
Correlation & -9.07 & -5.09 & -3.71 & \\
\hline \multicolumn{5}{c}{ Panel C: Nonresidential investment $(\alpha=0.1)$} \\
\hline$\xi$ & 10 & 2 & 0.45 & CRSP \\
\hline Mean & 3.55 & 4.10 & 7.41 & 7.86 \\
Std. Dev. & 1.00 & 2.66 & 10.91 & 17.14 \\
Correlation & -12.83 & -10.71 & -8.95 & \\
\hline \multicolumn{5}{c}{ Panel D: Residential investment $(\alpha=0.1)$} \\
\hline$\xi$ & 10 & 2 & 0.55 & CRSP \\
\hline Mean & 7.90 & 7.92 & 9.06 & 7.86 \\
Std. Dev. & 2.10 & 5.00 & 17.16 & 17.14 \\
Correlation & 7.74 & 16.57 & 18.19 \\
\hline \multicolumn{5}{c}{}
\end{tabular}


Table 2: Correlation of Investment Returns and Stock Returns

This table shows the correlation (in percent) of stock returns with gross investment returns, nonresidential investment returns, and residential investment returns at $k$ leads and lags, $\rho_{k}=\operatorname{Corr}\left(R_{t}^{E}, R_{t+k}^{I}\right), k=-4,-3, \ldots, 3,4$. The $t$-statistic of the null hypothesis of zero correlation, $H_{0}: \rho_{k}=0$, is reported in parenthesis. Correlation coefficients, which are significant at the $5 \%$ level, are marked with a *. The sample period is $1955-2004$.

\begin{tabular}{cccc}
\hline$k$ & Gross Inv. & Non-resid. Inv. & Resid. Inv. \\
\hline-4 & -2.93 & -8.40 & -2.40 \\
& $(-0.41)$ & $(-1.17)$ & $(-0.33)$ \\
-3 & $-13.93^{*}$ & -4.37 & -9.09 \\
& $(-1.96)$ & $(-0.61)$ & $-1.28)$ \\
-2 & -6.30 & -12.24 & -0.49 \\
& $(-0.88)$ & $(-1.73)$ & $-0.07)$ \\
-1 & -2.85 & -11.61 & 0.89 \\
& $(-0.40)$ & $(-1.64)$ & $(0.12)$ \\
0 & -4.10 & -8.95 & $18.19^{*}$ \\
& $(-0.58)$ & $(-1.27)$ & $(2.60)$ \\
1 & $18.61^{*}$ & 11.35 & $41.09^{*}$ \\
& $(2.66)$ & $(1.60)$ & $(6.33)$ \\
2 & $33.96^{*}$ & $31.08^{*}$ & $27.21^{*}$ \\
& $(5.06)$ & $(4.58)$ & $(3.96)$ \\
3 & $22.12^{*}$ & $24.33^{*}$ & 9.91 \\
& $(3.17)$ & $(3.50)$ & $(1.39)$ \\
4 & 1.88 & $22.36^{*}$ & -2.69 \\
& $(0.26)$ & $(3.20)$ & $(-0.37)$ \\
\hline
\end{tabular}


Table 3: Correlation of Investment Growth and Stock Returns

This table reports the correlation (in percent) of stock returns with gross investment growth, nonresidential investment growth, and residential investment growth at $k$ leads and lags, $\rho_{k}=\operatorname{Corr}\left(R_{t}^{E}, \Delta \ln I_{t+k}\right), k=-4,-3, \ldots, 3,4$. The $t$-statistic of the null hypothesis of zero correlation, $H_{0}: \rho_{k}=0$, is reported in parenthesis. Correlation coefficients, which are significant at the $5 \%$ level, are marked with a *. The sample period is $1955-2004$.

\begin{tabular}{cccc}
\hline$k$ & Gross Inv. & Non-resid. Inv. & Resid. Inv. \\
\hline-4 & -3.64 & -8.29 & -3.50 \\
& $(-0.51)$ & $(-1.16)$ & $(-0.49)$ \\
-3 & $-14.58^{*}$ & -4.86 & -9.88 \\
& $(-2.06)$ & $(-0.68)$ & $-1.39)$ \\
-2 & -5.74 & -12.62 & -1.84 \\
& $(-0.81)$ & $(-1.78)$ & $-0.26)$ \\
-1 & -3.90 & -12.60 & -1.65 \\
& $(-0.55)$ & $(-1.78)$ & $-0.23)$ \\
0 & -6.04 & -10.72 & $15.84^{*}$ \\
& $(-0.85)$ & $(-1.52)$ & $(2.26)$ \\
1 & $17.51^{*}$ & 10.49 & $41.22^{*}$ \\
& $(2.50)$ & $(1.48)$ & $(6.35)$ \\
2 & $34.20^{*}$ & $31.22^{*}$ & $28.03^{*}$ \\
& $(5.09)$ & $(4.60)$ & $(4.09)$ \\
3 & $23.50^{*}$ & $24.28^{*}$ & 11.30 \\
& $(3.38)$ & $(3.49)$ & $(1.59)$ \\
4 & 2.64 & $22.48^{*}$ & -0.06 \\
& $(0.37)$ & $(3.21)$ & $(-0.01)$ \\
\hline
\end{tabular}


Table 4: Benchmark Calibration

This table reports the benchmark parameter choice. $\beta$ denotes the household's discount rate and $\gamma$ the household's relative risk aversion; $\rho$ is the autocorrelation and $\sigma$ the standard deviation of the technology shock; $\alpha$ is the capital share and $\delta$ the depreciation rate of capital.

\begin{tabular}{lcc}
\hline Parameter & Symbol & Value \\
\hline Preferences: & & \\
$\quad$ Discount rate & $\beta$ & $1.03^{-1 / 4}$ \\
Risk aversion & $\gamma$ & 5 \\
Technology: & & \\
$\quad$ Autocorrelation & $\rho$ & 0.95 \\
$\quad$ Std. deviation & $\sigma$ & 0.007 \\
Production: & & \\
$\quad$ Capital elasticity & $\alpha$ & 0.36 \\
$\quad$ Depreciation & $\delta$ & 0.025 \\
\hline
\end{tabular}


Table 5: Moments

This table reports the moments of simulated models: In Model A, all project costs are due in the second period, i.e., $w=0$. In Model B, the costs are spread evenly over the two period construction period, i.e. $w=0.5$. In Model $\mathrm{C}$, the firm has to pay $20 \%$ of the costs in the initial period and, in addition, faces capital adjustment costs in the investment growth rate. $R^{E}$ denotes the return on equity, $R^{f}$ the risk-free rate, and SD its standard deviation. All asset pricing moments are annualized. $\sigma($.$) denotes the standard deviation, \mathbb{E}[$.$] the unconditional$ mean and $\operatorname{Corr}(.,$.$) the correlation between two variables.$

\begin{tabular}{cccc}
\hline Variable & Model A & Model B & Model C \\
\hline $\mathbb{E}\left[R^{E}\right]$ & 3.242 & 2.929 & 3.163 \\
$\sigma\left(R^{E}\right)$ & 7.593 & 1.601 & 5.209 \\
$\mathbb{E}\left[R^{E}-R^{f}\right]$ & 0.728 & 0.007 & 0.224 \\
$\mathbb{E}\left[R^{f}\right]$ & 2.514 & 2.922 & 2.940 \\
$\sigma\left(R^{f}\right)$ & 7.610 & 1.601 & 8.306 \\
$\sigma(C) / \sigma(Y)$ & 0.641 & 0.593 & 0.641 \\
$\sigma(I) / \sigma(Y)$ & 4.639 & 2.171 & 2.091 \\
$\operatorname{Corr}(C, Y)$ & 0.935 & 0.958 & 0.949 \\
$\operatorname{Corr}(I, Y)$ & 0.960 & 0.979 & 0.968 \\
\hline
\end{tabular}


Table 6: Model-based Correlation of Investment Returns and Stock Returns This table reports the correlation (in percent) of stock returns with gross investment growth, nonresidential investment growth, and residential investment growth at $k$ leads and lags, $\rho_{k}=$ $\operatorname{Corr}\left(R_{t}^{E}, R_{t}^{I}\right), k=-4,-3, \ldots, 3,4$. The $t$-statistic of the null hypothesis of zero correlation, $H_{0}: \rho_{k}=0$, is reported in parenthesis. The sample period is 1955-2004. In Model A, all project costs are due in the second period, i.e., $w=0$. In Model $\mathrm{B}$, the costs are spread evenly over the two construction periods, i.e., $w=0.5$. In Model C, the firm has to pay $20 \%$ of the costs in the initial period and, in addition, faces capital adjustment costs in the investment growth rate. All model versions are simulated for 5000 periods and investment returns are based on Equation (7) with $\xi=0.45$.

\begin{tabular}{ccccc}
\hline$k$ & Data & Model A & Model B & Model C \\
\hline-4 & -2.93 & 3.38 & 2.31 & -0.04 \\
& $(-0.41)$ & & & \\
-3 & -13.93 & -0.47 & 0.29 & -0.53 \\
& $(-1.96)$ & & & \\
-2 & -6.30 & -1.10 & 2.07 & -3.71 \\
& $(-0.88)$ & & & \\
-1 & -2.85 & -1.01 & 1.14 & -24.43 \\
& $(-0.40)$ & & & \\
0 & -4.10 & -67.72 & -8.22 & -41.25 \\
& $(-0.58)$ & & & \\
1 & 18.61 & 73.33 & 21.59 & 66.58 \\
& $(2.66)$ & & & \\
2 & 33.96 & 0.71 & -22.46 & 10.94 \\
& $(5.06)$ & & & \\
3 & 22.12 & 0.78 & 21.11 & 1.20 \\
& $(3.17)$ & & & \\
4 & 1.88 & -0.16 & -21.70 & 0.10 \\
& $(0.26)$ & & & \\
\hline
\end{tabular}


Table 7: Model-based Correlation of Investment Growth and Stock Returns This table reports the correlation (in percent) of stock returns with gross investment growth, nonresidential investment growth, and residential investment growth at $k$ leads and lags, $\rho_{k}=\operatorname{Corr}\left(R_{t}^{E}, \Delta \ln I_{t+k}\right), k=-4,-3, \ldots, 3,4$. The $t$-statistic of the null hypothesis of zero correlation, $H_{0}: \rho_{k}=0$, is reported in parenthesis. The sample period is 1955-2004. In Model A, all project costs are due in the second period, i.e., $w=0$. In Model B, the costs are spread evenly over the two construction periods, i.e., $w=0.5$. In Model $\mathrm{C}$, the firm has to pay $20 \%$ of the costs in the initial period and, in addition, faces capital adjustment costs in the investment growth rate.

\begin{tabular}{ccccc}
\hline$k$ & Data & Model A & Model B & Model C \\
\hline-4 & -8.29 & 3.43 & 12.52 & 0.11 \\
& $(-1.16)$ & & & \\
-3 & -4.86 & -0.26 & -9.91 & -0.53 \\
& $(-0.68)$ & & & \\
-2 & -12.62 & -0.99 & 12.92 & -3.58 \\
& $(-1.78)$ & & & \\
-1 & -12.60 & -0.59 & -9.55 & -24.46 \\
& $(-1.78)$ & & & \\
0 & -10.72 & -69.02 & 2.95 & -42.83 \\
& $(-1.52)$ & & & \\
1 & 10.49 & 72.45 & 11.05 & 65.52 \\
& $(1.48)$ & & & \\
2 & 31.22 & 0.90 & -11.53 & 11.10 \\
& $(4.60)$ & & & \\
3 & 24.28 & 1.01 & 11.10 & 1.51 \\
& $(3.49)$ & & & \\
4 & 22.48 & 0.13 & -11.38 & 0.44 \\
& $(3.21)$ & & & \\
\hline
\end{tabular}

